\title{
TRABALHO PEDAGÓGICO: UMA EXPERIÊNCIA COM A METODOLOGIA DE DIAGNÓSTICO RÁPIDO PARTICIPATIVO
}

\author{
PEDAGOGICAL WORK: AN EXPERIENCE WITH THE PARTICIPATIVE FAST \\ DIAGNOSTIC METHODOLOGY
TRABAJO PEDAGÓGICO: UNA EXPERIENCIA CON LA METODOLOGÍA DE DIAGNOSTICO RÁPIDO PARTICIPATIVO

\author{
Antônio Carlos Minussi Righes \\ E-mail: acmrighes@gmail.com \\ Instituto Federal de Educação, Ciência e Tecnologia Farroupilha - IFFar \\ Juliana Vaz Paiva \\ E-mail: julianavazpaiva@hotmail.com \\ Universidade Federal de Santa Maria - UFSM \\ Rosane Carneiro Sarturi \\ E-mail: rcsarturi@gmail.com \\ Universidade Federal de Santa Maria - UFSM
}

\begin{abstract}
RESUMO
Este artigo é resultado de uma pesquisa que teve como objetivo analisar em que aspectos a introdução da ferramenta Diagnóstico Rápido Participativo (DRP) contribui como técnica de avaliação formativa para discentes na disciplina de Gestão de Políticas Públicas, do Curso Superior de Tecnologia em Gestão Pública do Instituto Federal Farroupilha, Campus São Vicente do Sul. A pesquisa qualitativa foi baseada em um estudo de caso no IFFar/SVS. A metodologia constitui-se à luz de, dentre outros, Freire (1991, 2013), Dourado; Oliveira (2009), Brose (2010), Pacheco (2011), Eckert (2012), Gomes (2010), Maraschin (2015), Gimeno Sacristán (2017), Silva et al (2017), Ferreira (2018). Seguida de uma interpretação analítica de documentos legais basilares dos Institutos Federais, esta pesquisa considera também o relatório de dados da localidade de Dois Irmãos, município de São Vicente do Sul. Os resultados revelam a necessidade da criação de espaços de formação e reflexão para que haja aperfeiçoamento na formação de professores, assim como a realização de uma pesquisa para entender de forma mais eficaz o papel desta integração e seu impacto em todos os cursos. Deste modo, entende-se que faz parte da formação dos professores de educação dos Institutos Federais a capacidade de lidar didaticamente com públicos e níveis de ensino diversos, ainda que não possuem formação pedagógica inicial adequada.
\end{abstract}

Palavras chave. Diagnóstico Rápido Participativo. Trabalho pedagógico. Avaliação Formativa.

\section{ABSTRACT}

This article results from a research that aimed to analyze in which aspects the introduction of the Participatory Rapid Diagnosis (PRD) tool contributes as a formative evaluation technique, for students in the discipline of Public Policy Management, of the College Course in Technology in Public Management from IFFar, SVS.The qualitative research is based on a case study at the Instituto Federal Farroupilha, Campus São Vicente do Sul. The methodology is constituted, in the light of, among others, Freire (1991, 2013), Dourado; Oliveira (2009), Brose (2010), Pacheco (2011), Eckert (2012), Gomes (2010), Maraschin (2015), Gimeno Sacristán (2017), Silva et al (2017), Ferreira (2018). Followed by an analytical interpretation of basic legal documents from the Federal Institutes, that research considers the data report for Dois Irmãos, in the city of São Vicente do Sul. The results reveal the need of creating spaces for training and reflection so that there is an improvement in teacher training, as well as conducting research for a better understanding of the role of this integration and its impact on all 
courses. Thus, that the ability to deal didactically with diverse audiences and levels of education is a part of the training of education teachers at Federal Institutes, while they do not have adequate initial pedagogical training.

KEYWORDS: Rapid Participative Diagnosis. Pedagogical work. Teach learning.

\section{RESUMEN}

Este artículo presenta el resultado de una investigación cuyo objetivo es analizar en qué aspectos la implantación de la herramienta Diagnóstico Participativo Rápido (DPR) contribuye como técnica de evaluación formativa, para estudiantes de la asignatura de Gestión de Políticas Públicas, del Curso Superior de Tecnología en Gestión Pública del IFFar, SVS. La investigación cualitativa es basada en estudio de caso en el Instituto Federal Farroupilha, Campus São Vicente do Sul. La metodología se constituye, a la luz de Freire (1991, 2013), Dourado; Oliveira (2009), Brose (2010), Pacheco (2011), Eckert (2012), Gomes (2010), Maraschin (2015), Gimeno Sacristán (2017), Silva et al (2017), Ferreira (2018), entre otros. Seguido de una interpretación analítica de los documentos legales básicos de los Institutos Federales, considerando el informe de datos de la localidad Dois Irmãos, municipio de São Vicente do Sul. Los resultados revelan la necesidad de crear espacios de formación y reflexión para que haya una mejora en la formación docente, así como realizar investigaciones para comprender mejor el papel de la integración y su impacto en todos los cursos. De esta forma, se entiende que la capacidad para tratar didácticamente con públicos y niveles de educación diversos es parte de la formación de los docentes de educación en los Institutos Federales, a pesar de que no cuentan con una formación pedagógica inicial adecuada.

PALABRAS-CLAVE: Diagnóstico Participativo Rápido. Trabajo pedagógico. Enseñanza y aprendizaje.

\section{INTRODUÇ̃̃O}

Nesta pesquisa, abordam-se os elementos essenciais de um trabalho pedagógico, que resultou em uma avaliação de aprendizagem com a aplicação da metodologia do Diagnóstico Rápido Participativo (DRP). Importante ressaltar tratar-se de uma experiência prática com os alunos do Curso Superior de Tecnologia em Gestão Pública, turma GP3, no ano de 2011, do Instituto Federal de Educação, Ciência e Tecnologia Farroupilha, Campus São Vicente do Sul (IFFar/SVS).

Parte-se da argumentação de que a aplicação da ferramenta DRP compõe material para as atividades do trabalho pedagógico do docente, bem como possibilita a contribuição para a formação discente, com o conhecimento da teoria e a competência de compreender na prática a função de gestor público.

O IFFar/SVS foi instituído pela Lei ${ }^{\circ}$ 11.892, de 29 de dezembro de 2008 (BRASIL, 2008). O IFFar e seus campi assumiram o compromisso de servir como agentes promotores para o desenvolvimento regional, ofertando educação profissional e tecnológica, formando e qualificando cidadãos para atuarem nas mais diversas áreas, considerando o perfil formativo dos egressos no Curso Superior de Tecnologia em Gestão Pública (INSTITUTO FEDERAL DE EDUCAÇÃO, CIÊNCIA E TECNOLOGIA, 2014).

É importante destacar que os Institutos Federais (IFs) tem ênfase na proposta didático pedagógica, integrando uma formação geral com princípios humanistas e de base cultural ampla. Somado a isto, parte de contextos regionais, com formação para o trabalho, 
considerando a finalidade institucional na verticalização dos níveis de ensino, no espaço e tempo da territorialidade da interiorização e na transversalidade curricular (BRASIL, 2008).

Pacheco (2011, p. 23) entende que:

\begin{abstract}
A transversalidade, entendida como forma de organizar o trabalho didático, no caso da educação tecnológica, diz respeito principalmente ao diálogo educação e tecnologia. A tecnologia é o elemento transversal presente no ensino, na pesquisa e na extensão, configurando-se como uma dimensão que ultrapassa os limites das simples aplicações técnicas e amplia-se aos aspectos socioeconômicos e culturais.
\end{abstract}

Deste modo, a transversalidade e a verticalização são elementos que contribuem para a singularidade da dimensão didático-pedagógica do currículo dos cursos em todos os níveis ofertados pelos IFs.

Não há como contestar que o modelo dos IFs, no contexto das políticas públicas de educação profissional e tecnológica, é considerado inovador em termos de propostas políticopedagógicas, tendo por base o Documento de Concepções e Diretrizes dos IFs exarado em 2008 (INSTITUTO FEDERAL DE EDUCAÇÃO, CIÊNCIA E TECNOLOGIA, 2008).

$\mathrm{Na}$ proposta destas instituições, está um conceito de Educação Profissional e Tecnológica sem similares em outro país, uma organização pedagógica verticalizada que oferta cursos da Educação Básica à Superior (MARASCHIN, 2015).

Neste sentido, os cursos ofertados no IFFar apresentam a pesquisa aplicada tecnológica inserida em todos os cursos da verticalização, que são de Formação Continuada, Educação Básica Integrada à Educação Profissional, Programa Nacional de Integração da Educação Profissional com a Educação Básica na Modalidade de Educação de Jovens e Adultos (Proeja), Cursos Técnicos Subsequentes, Cursos Superiores de Graduação, Pós-Graduação e Cursos de Extensão, todos atendendo às demandas locais e regionais (INSTITUTO FEDERAL FARROUPILHA, 2014).

Nesta perspectiva, para alcançar a efetividade de ensino-aprendizagem, é importante que o docente articule atividades pertinentes ao plano de ensino, considerando as práticas com o trabalho de extensão, e, na pesquisa, a socialização dos resultados. Estas práticas pedagógicas estão atreladas ao processo de ensino-aprendizagem com os resultados para a avaliação discente, na lente dos trabalhos pedagógicos desenvolvidos nos momentos de formação dos alunos (FERREIRA, 2010). Diante deste contexto, Ferreira (2010) entende como trabalho pedagógico, todas as atividades cujas bases estejam, de alguma forma, relacionadas à área da pedagogia. Evidencia, portanto, métodos, técnicas e avaliação intencionalmente planejados, tendo em vista o alcance de objetivos relativos à produção de conhecimento. 
Ainda, busca-se a sustentação de Franco (2015, p. 603) para compreender o que se entende por pedagogia e didática. A autora esclarece que:

[...] a pedagogia coloca intencionalidades, projetos alargados; a didática comprometese a dar conta daquilo que se instituiu chamar de saberes escolares. A lógica da didática é a lógica da produção da aprendizagem (nos alunos), a partir de processos de ensino previamente planejados. A prática da didática é, portanto, uma prática pedagógica. A prática pedagógica inclui a didática e a transcende (FRANCO, 2015, p. 603).

Assim, entende-se que as práticas pedagógicas estão ligadas à pedagogia, e o processo de ensino aprendizagem constitui um elemento chave quando aplicadas metodologias e técnicas que contribuem para o aprendizado e a formação discente.

No que se refere à formação do professor, trata-se de uma metodologia que auxilia o ensino-aprendizagem, na arte de formar epistemologicamente, sendo considerada como um laboratório de reflexões e participação de todos. Neste sentido, o Diagnóstico Rápido Participativo é tido como uma metodologia de avaliação formativa, utilizada nas atividades de ensino, pesquisa e extensão. Deste modo, a proposta deste estudo gera relevância quando aplicada à ferramenta do DRP, pois, além de contribuir para o aprendizado dos alunos, tem como resultado o planejamento e a aplicação das ações de políticas públicas da educação profissional e tecnológica no contexto regional, o que aprimora a qualidade de vida dos moradores da localidade estudada, e contribui para o desenvolvimento local, para além de, como contrapartida, a própria formação discente.

O conceito de qualidade da educação, numa perspectiva polissêmica, mostra "[...] que a concepção de mundo, de sociedade e de educação evidencia e define os elementos para qualificar, avaliar e precisar a natureza, as propriedades e os atributos desejáveis de um processo educativo de qualidade social" (DOURADO; OLIVEIRA, 2009, p. 202). Esta qualidade apresentada pelos autores confirma que as práticas pedagógicas aderentes a este estudo possibilitam contribuição para o desenvolvimento social com ações pertinentes ao contexto investigado.

Encontra-se sustentação na teoria de Paiva $(2015$, p. 102) que afirma, com base na Lei n. ${ }^{\text { }} 11.892$, de 29 de dezembro de 2008, que "[...] ao definir a atuação, amplitude e a operacionalização dos Institutos Federais, conferiu-lhes perfil e características diferenciados de qualquer outra instituição de ensino existente na federação brasileira”.

Neste contexto, as metodologias do trabalho pedagógico - no caso do estudo, o DRP pode proporcionar uma formação profissional fundamentada no conhecimento da teoria/prática para os discentes e aprofundamento de conhecimentos para os docentes. 
Assim, esta pesquisa tem como objetivo analisar em que aspectos a introdução da ferramenta Diagnóstico Rápido Participativo (DRP) contribui como técnica de avaliação formativa, na disciplina de Gestão de Políticas Públicas, do Curso Superior de Tecnologia em Gestão Pública do Instituto Federal de Educação, Ciência e Tecnologia Farroupilha, Campus São Vicente do Sul.

A avaliação formativa ocorre durante o processo de ensino e de aprendizagem do discente, quando se identifica o nível de aprendizado do aluno e consideram-se as dificuldades de assimilação, para, então, haver a sugestão de atividades que proporcionem a superação destas. Este tipo de avaliação permite verificar se os alunos estão atingindo os objetivos propostos e quais os resultados alcançados durante o desenvolvimento das atividades de ensino. Hoffmann (1994) entende que a avaliação formativa constitui uma ação reflexiva e desafiadora entre os discentes e favorece aprendizados dos múltiplos conhecimentos. Nesta perspectiva, o DRP é utilizado em diversas atividades com o propósito de contribuir com a formação dos discentes.

A metodologia desta pesquisa constitui-se, primeiramente, na fundamentação teórica com base em autores que tratam da temática de pesquisa, como (DOURADO; OLIVEIRA, 2009), (BROSE, 2010), (PACHECO, 2011), (ECKERT, 2012), (GOMES, 2010), (MARASCHIN, 2015), (GIMENO SACRISTÁN, 2017), (SILVA et al, 2017), (FERREIRA, 2018), dentre outros. Seguida de uma interpretação analítica de documentos legais basilares dos Institutos Federais, a pesquisa considera também os dados do Relatório das entrevistas da comunidade de Dois Irmãos, município de São Vicente do Sul, Estado do Rio Grande do Sul. A análise dos dados para a sistematização da experiência, de acordo com a Análise de Conteúdo de Bardin (2016), foi construída levando em conta a triangulação de dados (documentos legais, entrevistas semiestruturadas e referencial teórico).

Face ao exposto, este estudo abona a sua pertinência e relaciona o conhecimento das estratégias de trabalhos pedagógicos no contexto das práticas profissionais relevantes para a formação profissional dos educandos, atendendo às dimensões de currículo apresentadas por Gimeno Sacristán (2017), em especial, ao currículo em ação, que apresenta a prática do professor como elemento básico a sustentar a ação pedagógica relacionada à qualidade real do ensino-aprendizagem, relacionando educador-educando e a complexidade em suas interações curriculares.

Portanto, a sistematização de experiência do DRP como metodologia da ação pedagógica mostra-se uma prática que contribui para a formação do educando. 


\section{DESCRIÇÃO DA EXPERIÊNCIA}

Com a intenção de apresentar uma metodologia que articule o ensino, pesquisa e extensão como prática pedagógica, destaca-se que foi desenvolvida neste estudo uma sistematização das experiências do DRP, com a participação dos alunos da turma da GP3.

Para Eckert (2012), a sistematização permite conhecer como se desenrolaram as experiências a partir das atividades realizadas, com o intuito de chegar aos resultados da pesquisa. Freire $(1991,2013)$ defende que a educação é efetivada na integração entre os indivíduos que participam no contexto em que vivem, e podem compreender o mundo antes mesmo da leitura da palavra, ou seja, compreendendo com a prática mais do que com o que está escrito sobre o que é realmente significativo em suas vidas.

Neste sentido, apresenta-se a experiência do Diagnóstico Rápido Participativo como estratégia de investigação da realidade do lócus de pesquisa, em que foi utilizado o DRP nas propostas de ensino, extensão e pesquisa, conforme detalhamento da figura 1 a seguir:

Figura 1 - Articulação do ensino, extensão e pesquisa nas atividades da metodologia do Diagnóstico Rápido Participativo (DRP).

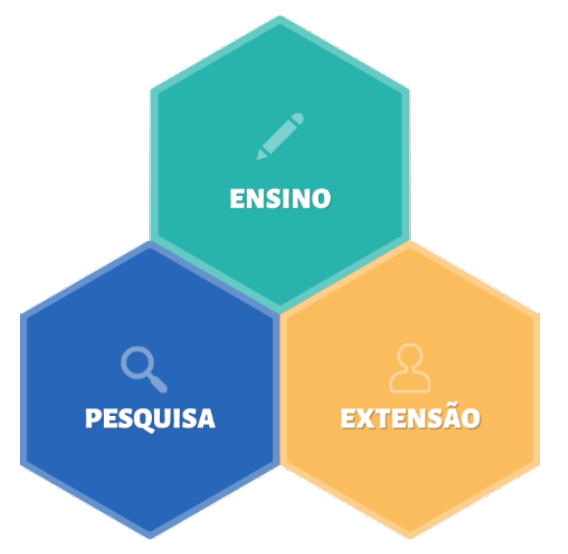

Fonte: Autores da pesquisa

Vale mencionar que, para as atividades de ensino, foi organizado, no primeiro dia de aula, um encontro com os alunos e professor, em que se apresentou o plano de ensino da disciplina de Gestão de Políticas Públicas. Estas propostas foram definidas como uma das avaliações formativas na aplicação da metodologia DRP para articular o ensino, a pesquisa e a extensão. Justifica-se esta atividade prática como método de avaliação formativa relevante para o conhecimento da prática na gestão pública, levando em conta que o cenário econômico, social, político, ambiental, tecnológico, cultural, demográfico, entre outros, são aspectos fundamentais para o resultado da investigação. 
Por conseguinte, para atingir o propósito do estudo, foi anunciado aos alunos que eles teriam aulas expositivas (conceitos do DRP e detalhamento da prática), apresentação de vídeos sobre a temática em experiências de DRP em diferentes ações, reuniões de debates com a comunidade de pesquisa e agentes da Empresa de Assistência Técnica e Extensão Rural (Emater-RS/Ascar) e reflexões sobre o contexto da realidade local. Além disso, seria desenvolvido um trabalho de campo com a proposta de identificar os problemas e as possibilidade de desenvolvimento da localidade visitada. Com base nos dados dos problemas encontrados, seriam articuladas com o grupo participante as possíveis ações promovedoras para o desenvolvimento social, político-legal, econômico, ambiental, tecnológico, cultural entre outros fatores determinantes para o progresso local. Por fim, seria elaborado um relatório apresentando os resultados das atividades. No último dia de aula, o documento seria entregue ao prefeito municipal. Cabe dizer que esta atividade foi organizada em parceria com os agentes da Emater e os líderes da comunidade de Dois Irmãos/Cerro do Loreto, município de São Vicente do Sul, estado do Rio Grande do Sul.

Na segunda fase, de extensão, foi realizada uma visita à localidade de Dois Irmãos, com a participação do docente, discentes, comunidade convidada, agentes da Emater, entre outras pessoas que contribuíram para o desenvolvimento do projeto. A acolhida aos moradores foi realizada no Núcleo de Tradições Gaúchas (NTG) e, no decurso da manhã, apresentada a proposta de trabalho.

Figura 2 - Alunos da turma GP3 do IFFar, professor e motorista.

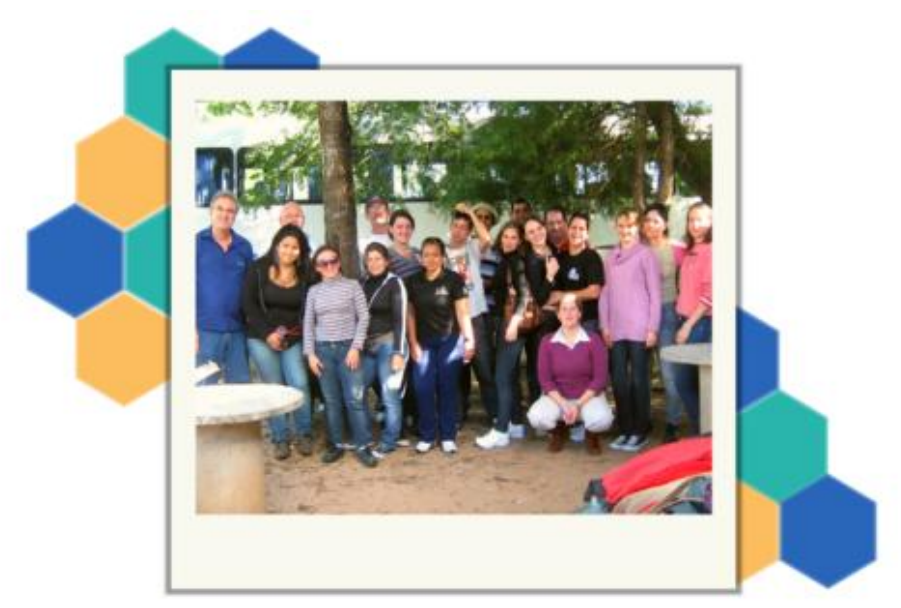

Fonte: Registro no momento da chegado do grupo da GP3, docente e motorista do IFFar, na localidade de Dois Irmãos.

Na aplicação do DRP, como metodologia de prática pedagógica para desenvolver uma atividade de Extensão, acredita-se que o trabalho de campo promove a construção de conhecimentos interdisciplinares a partir da realidade contada na experiência das atividades 
desenvolvidas na prática.

O mapa da localidade foi organizado com a colaboração dos líderes e moradores da comunidade, conforme se apresenta na Figura 3.

Figura 3 - Mapa territorial da comunidade de Dois Irmãos.

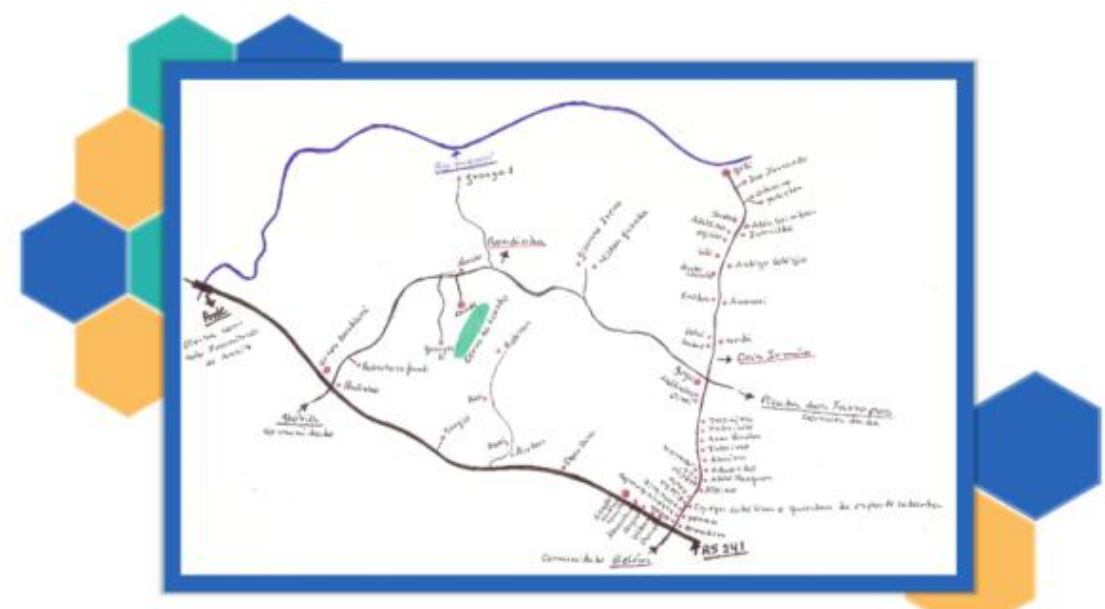

Fonte: Elaborado pelos alunos, moradores e líderes comunitários. Arquivo de imagens do Escritório Municipal da Emater/RS-Ascar de São Vicente do Sul.

A Figura 3 representa a comunidade de Rondinha, considerando o detalhamento do local, como a vocação econômica da localidade e os núcleos familiares. Concomitante ao desenho dos mapas, foram realizadas as entrevistas semiestruturadas com a participação dos representantes dos núcleos familiares.

Figura 4 - Mapeamento da comunidade do Loreto

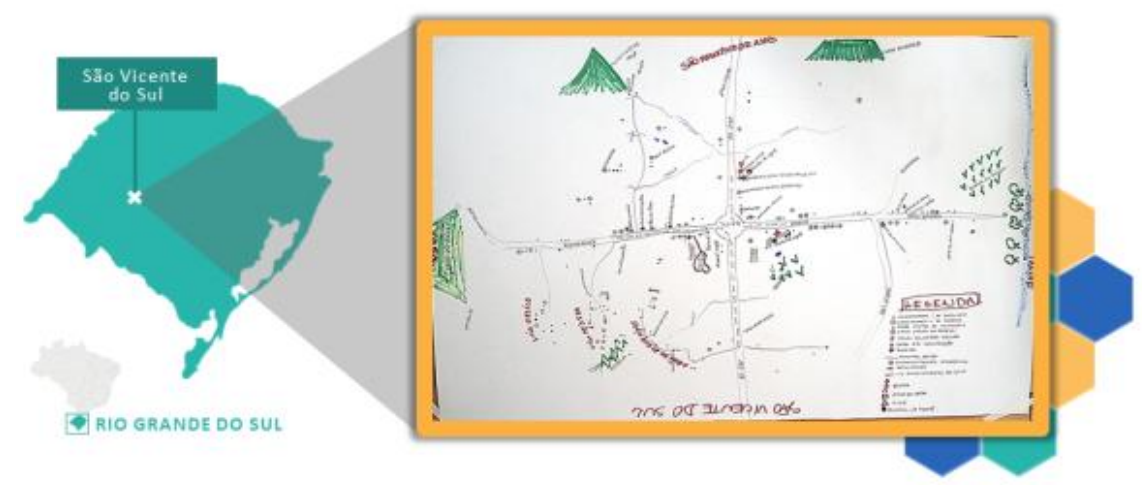

Fonte: Elaborado pelos alunos, moradores e líderes comunitários. Arquivo de imagens do Escritório Municipal da Emater/RS-Ascar de São Vicente do Sul.

O mapa da figura 4 apresenta os limites da comunidade, as estradas, os núcleos familiares informando o quantitativo de moradores e atividade econômica principal. O mapa orientou a pesquisa no sentido de conhecer o contexto da localidade. Destaca-se que esse mapa 
foi organizado em outro evento promovido pela Emater/RS-Ascar, com a participação dos líderes comunitários.

Figura 5 - Alunos e comunidade local, no momento da entrevista.

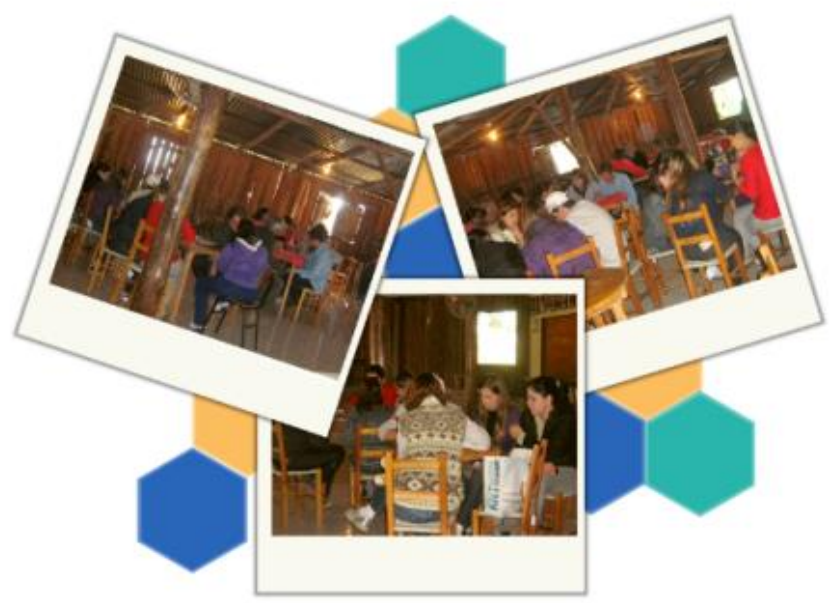

Fonte: Reunião com a comunidade local Cerro do Loreto - alunos e comunidade.

Durante a coleta das informações, o professor mediou as atividades e auxiliou os alunos nos questionamentos e na busca dos resultados da prática aplicada. Outros grupos de alunos fotografaram a localidade e prepararam o almoço oferecido à comunidade presente. Ressaltase que a atividade promoveu a integração do grupo, o que vem ao encontro dos propósitos da atividade DRP.

Figura 6 - Registro das atividades com a participação dos alunos da turma GP3

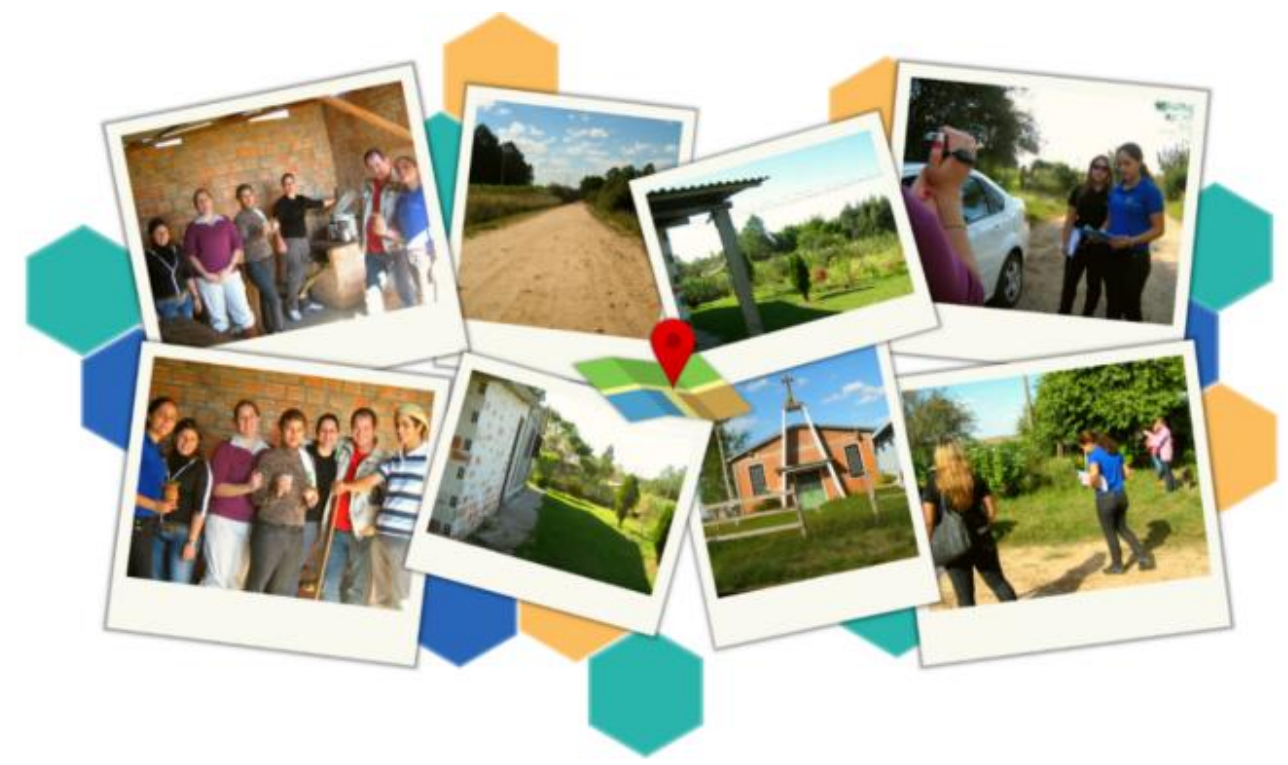

Fonte: Alunos da GP3 na organização do almoço; alunos realizando o percurso para identificar os problemas da comunidade. 
Logo após o almoço, foi organizada uma mesa redonda, com a mediação dos agentes da Emater e a participação do professor. Esta atividade possibilitou conhecer os problemas enfrentados pela sociedade do Cerro do Loreto.

Com os dados parciais, foram discutidas e elencadas algumas ações estratégicas para melhorar a qualidade de vida dos moradores da localidade. As anotações foram feitas pelos alunos e discutidas no grupo, junto das petições para aprimorar a qualidade de vida dos habitantes da localidade. Às cinco da tarde, os alunos retornaram para o IFFar/SVS e, do local, dispersaram para as suas residências.

$\mathrm{Na}$ terceira fase, os dados foram socializados e registrados em alguns eventos acadêmicos. Em sala de aula, foram discutidos os resultados e combinada sua divulgação com alguns alunos, conforme apresentado na metodologia desta pesquisa.

\section{PROCEDIMENTOS METODOLÓGICOS}

A proposta metodológica deste estudo está fundamentada nas experiências da metodologia DRP. Para Gomes (2010), o Diagnóstico Rápido Participativo consiste num método utilizado para fazer levantamento da realidade local. Geralmente feito com a participação das lideranças locais ou integrantes de um grupo definido, este levantamento apresenta o contexto real da localidade com os dados dos principais problemas em todas as áreas (social, econômica, cultural, ambiental, físico-territorial e político-institucional, entre outras).

Assim, dos 29 instrumentos de metodologia participativa, da obra de Markus Brose (2010), a metodologia DRP foi escolhida para uma das avaliações formativas dos acadêmicos da turma de GP3, na disciplina de Gestão de Políticas Públicas, do Curso Superior de Tecnologia em Gestão Pública, do IFFar/SVS, Estado do Rio Grande do Sul.

De acordo com Gomes (2010), uma das vantagens da metodologia DRP refere-se à possibilidade de o grupo participante socializar as informações coletadas. Desta forma, compreende-se que, ao socializar as informações de interesse do grupo, emergem fatos e tensiona-se a discussão com a apresentação das potencialidades e fragilidades locais. Isto permite articular ações de políticas públicas para o desenvolvimento local.

Para esta prática pedagógica, foi organizada atividade considerando a articulação do ensino, da extensão e da pesquisa, detalhada na sistematização da experiência. As figuras hexagonais, apresentadas nas imagens, representam a integração das dimensões ensinopesquisa-extensão. A atividade interdisciplinar, ofertada no $3^{\circ}$ semestre do curso, vinculou o 
processo de ensino-aprendizagem com os seguintes componentes curriculares: Gestão de Políticas Públicas; Finanças e Orçamento Público; Estado e Sociedade; e Políticas de Desenvolvimento Econômico, com a coordenação do professor da Disciplina de Gestão de Políticas Públicas.

A organização das disciplinas teve como base a representação gráfica do perfil do egresso no curso superior em Tecnologia em Gestão Pública IFFar/SVS, compilada do Projeto Pedagógico do Curso Superior de Tecnologia em Gestão Pública, reformulado pela Resolução Ad Referendum $\mathrm{n}^{\circ}$ 16/2012 de 20/04/2011. (INSTITUTO FEDERAL DE EDUCAÇÃO, CIÊNCIA E TECNOLOGIA FARROUPILHA, 2014).

Os horizontes pedagógicos relacionados à interdisciplinaridade equivalem aos passos que se deve tomar, a fim de construir uma matriz curricular que supere as rígidas fronteiras disciplinares (SILVA et al, 2017). Assim, a disciplina de Gestão de Políticas Públicas proporcionou a Prática Profissional Integrada (PPI) com as outras disciplinas do $3^{\circ}$ semestre, conforme anunciado no Projeto Pedagógico do Curso Superior de Tecnologia em Gestão Pública do IFFar/SVS. Destaca-se que a metodologia de ensino-aprendizagem da PPI teve como base a autonomia dos docentes na articulação dos resultados do relatório, tratando os dados constatados conforme o conteúdo programático da disciplina.

Para organizar as atividades, em uma sala de aula do IFFar/SVS, foi marcada uma reunião de abertura no segundo semestre do ano letivo de 2011. Contou com a presença do professor e 29 alunos do Curso de Gestão Pública (GP3), bem como de dois agentes da Emater RS/Ascar, que apresentaram algumas localidades do município de São Vicente do Sul como sugestão para desenvolver o DRP. Dentre as localidades elencadas, foi escolhida a comunidade de Dois Irmãos/Cerro do Loreto, situada às margens do Rio Jaguari, a $20 \mathrm{~km}$ da sede do município de São Vicente do Sul, formada há mais de 35 anos (RIGHES et al, 2012).

Cabe salientar que, para Yin (2015), o estudo de caso pode ser utilizado com o intuito de levantar questões e hipóteses na pesquisa realizada entre um ou mais objetos de investigação. Para Gil (2010), o estudo de caso possibilita aprofundar a investigação sobre o objeto, uma organização, um grupo, podendo ser aplicado às mais diversas áreas do conhecimento. Tanto para Yin (2015) como Gil (2010), o estudo de caso permite que o objeto estudado tenha preservada sua identidade, bem como propicia a explicação de variáveis em situações ainda que complexas. Assim, o estudo de caso neste trabalho oportunizou compreender como aconteceu o processo da sistematização da experiência do Cerro do Loreto, município de São Vicente do Sul. 
$\mathrm{Na}$ busca da efetividade do processo, a parceria com os agentes da Emater foi o canal de relacionamento entre moradores e agentes, com a intenção de abrir espaço na localidade, considerando a credibilidade do órgão público.

A experiência de Extensão aconteceu no dia 15 de maio de 2011, com a chegada na localidade às 9 horas da manhã, quando da abertura do evento no Núcleo de Tradições Gaúchas (NTG) da Escola Antero Xavier. Estavam presentes dois líderes comunitários, 28 representantes das unidades familiares da localidade, dois agentes da Emater, duas bolsistas do Programa Institucional de Incentivo à Extensão (PIIEX) do IFFar/SVS, um motorista do IFFar, um docente, 21 alunos da turma GP3 do IFFar/SVS, e dois vereadores representando a localidade, entre outros simpatizantes.

Cabe destacar que essa atividade fez parte do projeto "Planejamento Local Participativo no Cerro do Loreto, município de São Vicente do Sul”, registrado no departamento de Extensão do IFFar/SVS, oriundo do Edital de 2010 do PIIEX. As atividades foram realizadas em 2011, coordenadas pelo professor de Gestão de Políticas Públicas.

Para a recepção dos convidados, foi organizado um almoço de confraternização no NTG. Cabe dizer que o transporte de ida e volta, para alunos e professor, foi cedido pelo IFFar/SVS.

Durante a festividade, sob a responsabilidade dos alunos, foram coletadas as informações organizadas na sistematização das entrevistas. As perguntas essencialmente questionaram problemas enfrentados pelos moradores na localidade, levando em conta, entre outros assuntos que emergiram nas categorias de análise, os eixos da infraestrutura local, saneamento básico, saúde, educação, segurança pública, lazer, atividades econômicas e agricultura familiar.

Na parte da tarde, com a finalidade de constatar os problemas apresentados para o grupo de pesquisa, os alunos, com os líderes da comunidade, professor e agentes da Emater, visitaram as residências dos moradores que participaram do evento.

Feitas as entrevistas, utiliza-se o método da matriz de priorização de problemas. $\mathrm{O}$ coordenador da atividade organiza um mural e identifica os principais problemas enfrentados pela comunidade. Elencados os problemas, cada participante da reunião é convidado a marcar seu voto no item que acredita ser mais importante a ser resolvido. Ao final da atividade, é possível conhecer, em ordem de prioridade, as ações escolhidas do maior ao menor quantitativo de votos. (GOMES, 2010).

A atividade da "matriz de prioridades dos problemas" foi organizada de forma participativa, na qual os alunos e moradores elegeram as prioridades de ações para os problemas 
encontrados. Como metodologia, adotou-se o critério de que seria decidida uma ação de aprimoramento para cada problema encontrado (ponto fraco e ameaça). Todos os participantes foram registrados na lista de presença e, posteriormente ao evento, receberam um certificado de participação expedido pelo Departamento de Extensão do IFFar/SVS. Para os alunos, os certificados foram validados como atividades complementares, computadas 30 horas de atividades, considerando o planejamento da atividade, o desenvolvimento e a organização do relatório. Além disso, para a divulgação das entrevistas semiestruturadas e as imagens das fotografias, os atores da pesquisa assinaram Termos de Consentimento Livre e Esclarecido (TCLE), os quais ficaram armazenados por cinco anos no Bloco A, sala 14, do IFFar/SVS.

Ao término das atividades, o grupo participante despediu-se dos moradores da comunidade e se dispersou no IFFar/SVS.

$\mathrm{Na}$ sequência das atividades, em sala de aula, os alunos organizaram um Relatório Final da atividade, em que apresentaram os resultados tabulados e analisados. Com a intenção de publicizar a atividade, com a participação do prefeito municipal de São Vicente do Sul, foi realizada uma aula em que houve a entrega do documento.

A análise dos dados constitui-se, primeiramente, na fundamentação teórica com base nos autores referentes à temática de pesquisa, dentre outros, como: Dourado; Oliveira (2009), Brose (2010), Pacheco (2011), Eckert (2012), Gomes (2010), Righes; Rocha (2012), Paiva (2015), Ferreira (2018), seguida de uma interpretação analítica da Lei $n^{\circ} 11.892$, de 29 de dezembro de 2008 (BRASIL, 2008), e também com os dados do Relatório das entrevistas da comunidade de Dois Irmãos, município de São Vicente do Sul, Estado do Rio Grande do Sul. A análise dos dados foi construída também de acordo com a Análise de Conteúdo de Bardin (2016).

Nas atividades de pesquisa, os dados foram socializados nos seguintes eventos:

a) Anais do Congresso Latino Americano de Sustentabilidade Socioambiental: Espaços Rurais e Contemporaneidade, realizado nos dias 12 a 15 de junho de 2012, no CTG Sentinela da Querência, em Santa Maria, RS;

b) Livro de Experiências Inovadoras em Extensão Rural na Agricultura Familiar Região de Abrangência do Instituto Federal Farroupilha, Campus São Vicente do Sul. São Vicente do Sul/ RS: IF Farroupilha, 2012, v. 1, p. 241-255;

c) Anais do COLASER - Congresso Latinoamericano de Sustentabilidade, 2012, Santa Maria. Congresso Latinoamericano de Sustentabilidade Socioambiental: Espaços Rurais e Contemporaneidade (12 a 15 de junho de 2012) Santa Maria/RS, 2012. v.1. p. 31 - 45; 
d) Resumo dos Anais do IV Jornada de Iniciação Científica e Tecnológica do IFSUL, 2011, Pelotas/RS.

Portanto, a metodologia utilizada alcançou o objetivo da pesquisa, considerando a aproximação entre alunos, professores, comunidade. Além disso, os alunos conheceram na prática a metodologia experienciada e articularam em seus aprendizados o ensino, a pesquisa e a extensão.

\section{RESULTADOS E DISCUSSÃO}

Os dados apresentados e analisados contemplam as questões de pesquisa e buscam responder ao objetivo principal deste trabalho. Dos vários resultados obtidos com esta experiência, salienta-se que a aplicação na prática do DRP, como trabalho pedagógico, possibilitou a integração entre o grupo participante. Além disso, permitiu aos alunos conhecerem, na prática, a função de gestor público, levando em consideração a complexidade da atividade vivenciada.

Após a experiência, no retorno para o IFFar/SVS, foi perguntado ao grupo de alunos como eles haviam avaliado a experiência do Diagnóstico Rápido Participativo como atividade de gestão. As respostas ratificaram o compromisso de dar prosseguimento à prática, bem como da satisfação dos alunos em participar da atividade. Conforme os relatos apresentados:

Professor! Gostei de participar desta prática, aprendemos um montão. (Discurso do aluno A);

Queremos participar de outras vezes. (Discurso do aluno B);

Que gente legal aquela da comunidade, eles ajudaram nós a desenhar e conhecer a realidade deles.(Discurso do aluno C);

Colegas! Que legal a experiência, eu não sabia que eles tinham tantos problemas lá fora. (Discurso do aluno D).

Outro resultado diz respeito à melhora significativa da participação dos alunos em sala de aula, estimulando auspiciosa curiosidade para compreender os meandros da gestão pública e da administração de um município.

Por fim, destaca-se igualmente o resultado quanto à participação da comunidade local nas atividades, à parceria com os agentes da Emater e à disponibilidade do motorista que nos guiou até o local da pesquisa. Pelos resultados positivos, a atividade foi repetida com outras turmas, em outras localidades sugeridas pelos agentes da Emater. No caso da localidade de Cavajuretã, com a turma GP2, no ano de 2010, esta atividade rendeu duas participações em 
eventos e uma publicação com a participação das duas bolsistas do PIIEX ${ }^{1}$, em parceria com o professor coordenador da atividade. Esta atividade estava vinculada ao projeto "Experiências Inovadoras em Extensão Rural na Agricultura Familiar na Região de Abrangência do Instituto Federal de Educação, Ciência e Tecnologia Farroupilha", Edital PIIEX, 2010. Com base no Relatório final da atividade foram socializados os dados em eventos:

a) Resumo dos Anais do IV Jornada de Iniciação Científica e Tecnológica do IFSUL, 2011, Pelotas/RS. Desenvolvimento Local e Políticas Públicas: O caso do distrito de Cavajuretã - município de São Vicente do Sul/, 2011;

b) Resumo dos Anais da II Mostra de Educação Profissional e Tecnológica, II Seminário de Ensino, Pesquisa e Extensão, I Ciclo de Estudos, Santa Rosa/RS, 2011.

No ano de 2012, foi contemplada para a atividade do DRP a localidade do Rincão dos Esquecidos, município de São Vicente do Sul. Participaram desta atividade os alunos da turma GP4 do IFFar, docente, bolsistas, agentes da Emater e representantes da comunidade local. A atividade estava relacionada ao projeto "Apoio permanente a Gestão Pública e o Desenvolvimento Socioeconômico nos municípios do entorno do Instituto Federal de Educação, Ciência e Tecnologia Farroupilha”, Campus São Vicente do Sul, vinculado ao Edital do PIIEX 2012.

Diante destes resultados, é inegável afirmar que a prática do DRPmostrou-se relevante para o aprendizado, na teoria e na prática, para o docente e os alunos da turma GP2, GP3 e GP4. Os efeitos da atividade comprova os resultados. Fica evidente que o trabalho pedagógico contribui para a formação dos alunos.

\section{CONSIDERAÇÕES FINAIS}

Os fatos tratados, nas experiências deste estudo, explicitaram a complexidade da organização do trabalho docente no caso dos Instituto Federal de Educação, Ciência a Tecnologia Farroupilha, Campus São Vicente do Sul, e compreendem um convite à reflexão sobre a Educação Básica Técnica e Tecnológica.

Afirma-se que as práticas pedagógicas inovadoras contribuem para a avaliação formativa do aluno. Além disso, permitem a interlocução entre docente e discentes. Neste sentido, das trocas de experiências dos trabalhos pedagógicos emergem conhecimentos que se transformam em qualidade de ensino.

\footnotetext{
${ }^{1}$ Programa Institucional de Incentivo à Extensão - PIIEX Farroupilha, aprovado pela Resolução no 73/2011 do Conselho Superior, teve em 2011 seu segundo ano de edição.
} 
Conforme Dourado; Oliveira (2009), a qualidade de ensino no contexto das práticas pedagógicas advém da possibilidade de articular a teoria e a prática para a formação integral do educando. Sendo assim, os resultados comprovaram a utilização da ferramenta de Diagnóstico Rápido Participativo como prática e método de avaliação na disciplina de Gestão de Políticas Públicas do Curso Superior de Tecnologia em Gestão Pública, do IFFar/SVS.

Constata-se que a metodologia participativa, de acordo com Gomes (2010), possibilitou ao aluno conhecer a realidade da localidade de Dois Irmãos, município de São Vicente do Sul. Frente aos resultados, considera-se que a prática oportunizou aos alunos a relação dos conteúdos das disciplinas, levando em conta a interdisciplinaridade curricular, com a tomada de decisão de um gestor público. Igualmente, oportunizou a interlocução do grupo, aproximando-os de forma participativa na construção das ações. Além do mais, permitiu ao professor transcender os métodos de avaliação com a apropriação de um conceito. Portanto, o DRP evidencia uma metodologia de aprendizado e de avaliação a ser aplicada em qualquer nível e modalidade de ensino, desde que atenda a prerrogativas da ementa do componente curricular do Projeto Pedagógico do Curso.

\section{REFERÊNCIAS}

BARDIN, L. Análise de conteúdo. São Paulo: Edições 70, 2016.

BRASIL. Lei n. ${ }^{\circ}$ 11.892, de 29 de dezembro de 2008. Institui a Rede Federal de Educação Profissional, Científica e Tecnológica, cria os Institutos Federais de Educação, Ciência e Tecnologia, e dá outras providências. Brasília, 2008.

BROSE, M. (Org.) Metodologia participativa: uma introdução a 29 instrumentos. 2. ed. Porto Alegre: Tomo Editorial, 2010.

ECKERT, C. Sistematização de Experiências: Contribuindo para a construção de saberes e uma ferramenta para o planejamento. In: Experiências Inovadoras em Extensão Rural na Agricultura Familiar Região Abrangência do Instituto Federal Farroupilha Campus São Vicente do Sul/ Gustavo Pinto da Silva, Rafaela Vendruscolo (Orgs.). São Vicente do Sul/RS: IF Farroupilha, Campus São Vicente do Sul, 2012.

FRANCO, M. A. S. Práticas pedagógicas de ensinar-aprender: por entre resistências e resignações. Educ. Pesqui., São Paulo, v. 41, n. 3, p. 601-614, jul./set. 2015. http://dx.doi.org/10.1590/S1517-9702 2015 07140384. Disponível em: https://www.scielo.br/pdf/ep/v41n3/1517-9702-ep-41-3-0601.pdf

FERREIRA, L. S. Trabalho Pedagógico na Escola: do que se fala? Educação \& Realidade, Porto Alegre, v. 43, n. 2, p. 591-608, abr./jun. 2018. DOI: http://dx.doi.org/10.1590/2175623664319: Disponível em http://www.scielo.br/pdf/edreal/v43n2/2175-6236-edreal-43-02591.pdf 
FERREIRA, L. S. Trabalho pedagógico. In: OLIVEIRA, Dalila Andrade et al.

DICIONÁRIO: Trabalho, profissão e condição docente. Belo Horizonte: UFMG/Faculdade de Educação, 2010. CDROM.

FREIRE, P. A importância do ato de ler: em três artigos que se completam. São Paulo: Cortez \& Autores Associados, 1991.

FREIRE, P. Pedagogia da autonomia: saberes necessários à prática educativa. 47. ed. São Paulo: Paz e Terra, 2013.

GIL, A. C. Como elaborar projetos de pesquisa. 5. ed. São Paulo: Atlas, 2010.

GIMENO SACRISTÁN, J. O currículo: uma reflexão sobre a prática. Tradução: Ernani F. da Fonseca Rosa. Revisão técnica: Maria da Graça Souza Horn. 3. ed. Porto Alegre: Penso, 2017.

GOMES, M. A. O. Diagnóstico Rápido Participativo (DRP): uma ferramenta de ação e aprendizagem coletiva. In: BROSE, Markus (Org.) Metodologia participativa: uma introdução a 29 instrumentos. 2. ed. Porto Alegre: Tomo Editorial, 2010. p. 67-80.

HOFFMAN, J. M. L. Avaliação mediadora: uma relação dialógica na construção do conhecimento. In: ALVES, Maria Leila et al. (Org.) Avaliação do rendimento escolar. São Paulo: FDE, 1994. p. 51-59.

INSTITUTO FEDERAL DE EDUCAÇÃO, CIÊNCIA E TECNOLOGIA FARROUPILHA. Plano de Desenvolvimento Institucional (PDI), IFFar. (2014-2018). Disponível em: https://www.iffarroupilha.edu.br/documentos-do-pdi/item/8369-plano-de-desenvolvimentoinstitucional-2014-2018.

INSTITUTO FEDERAL DE EDUCAÇÃO, CIÊNCIA E TECNOLOGIA FARROUPILHA. Projeto Pedagógico do Curso Superior de Tecnologia em Gestão Pública. Aprovado na 3. . Reunião Extraordinária de 2008 - Ata n. ${ }^{\circ} 38$ Resolução do Conselho Diretor N. ${ }^{\circ} 23 / 2008$, de 14/11/2008. Reformulado pela Resolução Ad Referendum n. ${ }^{\circ}$ 16/2012 de 20/04/2011. Reformulado pela Resolução Ad Referendum n. ${ }^{\circ}$ 62/2012, de 07/12/2012, 2014. Disponível em:

file://C:/Users/acmri/Downloads/Tecnologia $\% 20 \mathrm{em} \% 20 \mathrm{Gest} \% \mathrm{C} 3 \% \mathrm{~A} 30 \% 20 \mathrm{P} \% \mathrm{C} 3 \% \mathrm{BAblic}$ as $\% 20(9) . p d f$

INSTITUTO FEDERAL DE EDUCAÇÃO, CIÊNCIA E TECNOLOGIA FARROUPILHA. Relatório de Gestão do Exercício 2011. Santa Maria/RS, março/2012. Disponível em: https://www.iffarroupilha.edu.br/component/k2/attachments/download/4445/87d5e8bd5454c7 d2d797c98b89a61734>

MARASCHIN, M. S. Dialética das disputas: trabalho pedagógico a serviço da classe trabalhadora? 2015, p. 316. Tese (Doutorado em Educação). Universidade Federal de Santa Maria, Santa Maria, RS, 2015.

PACHECO, E. (Org.). Institutos Federais: uma revolução na educação profissional e tecnológica. Brasília: Fundação Santillana; São Paulo: Moderna. 2011. 
PAIVA, L. D. C. Autoavaliação institucional: perspectivas no âmbito dos Institutos Federais. Curitiba: Appris, 2015.

RIGHES, A. C. M et al. Lideranças Rurais no Município de São Vicente do Sul/RS. In:

Experiências Inovadoras em Extensão Rural na Agricultura Familiar Região Abrangência do Instituto Federal Farroupilha Campus São Vicente do Sul / Gustavo Pinto da Silva, Rafaela Vendruscolo (Org.) São Vicente do Sul / RS: IF Farroupilha, Campus São Vicente do Sul, 2012. p. 241-255.

RIGHES, A.C.M; ROCHA, E. P. Diagnóstico socioeconômico como base para as ações de políticas públicas na comunidade Dois Irmãos do distrito do Loreto Município de São Vicente do Sul/RS In: COLASER - Congresso Latino Americano de Sustentabilidade, 2012, Santa Maria. Congresso Latino Americano de Sustentabilidade Socioambiental: Espaços Rurais e Contemporaneidade (12 a 15 de junho de 2012) Santa Maria / RS, 2012. v.1. p. $31-45$.

SILVA, C. et al. Licenciatura em Educação do Campo com habilitação em Artes e Música: Trajetória e desafios na região do Bico do Papagaio, Brasil. Revista Triângulo, v. 10, n. 1. Jan./Jun. 2017. DOI: https://doi.org/10.18554/rt.v10i1.2186. Disponível em: http://seer.uftm.edu.br/revistaeletronica/index.php/revistatriangulo/article/view/2186/0

YIN, R. Estudo de caso: planejamento e método. 5. ed. São Paulo: Bookman, 2015. 